\title{
MicroRNA-497 suppresses osteosarcoma tumor growth in vitro and in vivo
}

\author{
LIANG GE $^{1}$, BAISONG ZHENG ${ }^{2},{\text { MINGHE } \mathrm{LI}^{3} \text {, LIANG NIU }}^{4}$ and ZHIHONG LI ${ }^{5}$ \\ ${ }^{1}$ Department of Anesthesiology; ${ }^{2}$ Institute of Virology and AIDS Research, \\ The First Hospital of Jilin University, Changchun, Jilin 130021; ${ }^{3}$ Department of Oral and Maxillofacial Surgery, \\ School of Stomatology Hospital of Jilin University, Changchun, Jilin 130000; ${ }^{4}$ Operating Room; \\ ${ }^{5}$ Department of Thoracic Surgery, The First Hospital of Jilin University, Changchun, Jilin 130021, P.R. China
}

Received December 5, 2014; Accepted December 8, 2015

DOI: $10.3892 / \mathrm{ol} .2016 .4162$

\begin{abstract}
It has been demonstrated that microRNA-497 (miR-497) acts as a tumor suppressor and is involved in tumor progression, development and metastasis in several types of cancer. However, little is known about the exact role of miR-497 in osteosarcoma (OS). The aim of the current study was to investigate the potential role of miR-497 in human OS. The role of miR-497 in the growth and survival of OS cells was determined using several in vitro approaches and a nude mouse model. The results demonstrated that exogenous expression of miR-497 in human OS MG63 cells suppressed cell proliferation, colony formation, migration and invasion, and induced cell apoptosis and cell arrest at the G0/G1 phase of the cell cycle. In addition, the results of the in vivo study indicated that restoration of miR-497 inhibited OS tumor growth in a nude mouse model. Overall, the results of the present study identified a crucial tumor suppressive role of miR-497 in the progression of OS, and suggested that miR-497 may be a potential therapeutic agent for the treatment of OS.
\end{abstract}

\section{Introduction}

Osteosarcoma (OS) is the most frequent primary malignant bone tumor in children and young adolescents $(1,2)$. The survival rates for OS have improved considerably since the introduction of multi-agent chemotherapy in the 1980s, with a 5-year overall survival rate of $60-65 \%$ for patients without metastasis (3), and have remained relatively constant for the past two decades $(4,5)$. The development of conventional OS is a multistep process characterized by genetic and epigenetic alterations that affect key cellular pathways involved in cell growth and development (6). Therefore, an improved

Correspondence to: Professor Zhihong Li, Department of Thoracic Surgery, The First Hospital of Jilin University, 71 Xinmin Street, Changchun, Jilin 130021, P.R. China

E-mail: lizhihong5436@126.com

Key words: osteosarcoma, microRNAs, miR-497, tumor growth understanding of the molecular mechanisms involved in OS initiation and progression may contribute to the identification of a therapeutic target for the treatment of OS, which may additionally improve the overall outcome of patients with OS.

MicroRNAs (miRNAs) are a family of small non-coding RNAs (19-25 nucleotides long), which are involved in the regulation of gene expression by inducing messenger (m)RNA degradation or repressing mRNA translation (7). miRNAs have been demonstrated to be involved in numerous physiological processes, including cell growth, apoptosis, development and tumorigenesis (7-12). miRNAs may act as oncogenes or tumor suppressors in the regulation of carcinogenesis, metastasis and drug resistance (10), and are considered to be biomarkers for the diagnosis of various types of cancer and potential novel targets for anticancer therapies (13).

miRNA-497 (miR-497), an important member of the miR-15/16/195/424/497 family of miRNAs (14), is downregulated in various types of cancer, including ovarian (15), breast (16), colorectal (17) and cervical cancer (18). Previous studies have demonstrated that miR-497 exerts a tumor suppressor function in human colorectal cancer (17), cervical cancer (18), breast carcinoma (16), neuroblastoma (19), gastric cancer (20) and ovarian cancer $(15,21)$. In addition, miR-497 has been observed to be downregulated in OS cell lines, compared with normal bone cells, using miRNA microarray profiling in an integrative expression profiling approach (22). However, the exact role of miR-497 in OS remains relatively unknown. Therefore, the aim of the current study was to investigate the role of miR-497 in OS in vitro and in vivo in order to determine the potential use of miR-497 in OS therapy.

\section{Materials and methods}

Cell lines and cell culture. Human OS MG63 cells were obtained from the Shanghai Institute of Biochemistry and Cell Biology of the Chinese Academy of Sciences (Shanghai, China). The cells were cultured in RPMI-1640 medium (Sigma-Aldrich, St. Louis, MO, USA) supplemented with $10 \%$ Gibco fetal calf serum (FCS; Thermo Fisher Scientific, Inc., Waltham, MA, USA), $100 \mathrm{U} / \mathrm{ml}$ penicillin (Sigma-Aldrich) and $100 \mathrm{mg} / \mathrm{ml}$ streptomycin (Sigma-Aldrich), and maintained 
at $37^{\circ} \mathrm{C}$ in a humidified atmosphere containing $5 \% \mathrm{CO}_{2}$. The complete medium was replaced every 2-3 days.

miRNA transfection. miR-497 mimic and negative control miRNA (Shanghai GenePharma Co., Ltd., Shanghai, China) were transiently transfected into MG63 cells in 6-well plates (Sigma-Aldrich) using $100 \mathrm{nM}$ Invitrogen Oligofectamine ${ }^{\mathrm{TM}}$ Transfection Reagent (Thermo Fisher Scientific, Inc.), according to the manufacturer's protocol.

Reverse transcription-quantitative polymerase chain reaction $(R T-q P C R)$. Total RNA was extracted from MG63 cells transfected with miR-497 mimic or negative control miRNA, or from tumors of mice inoculated with cells overexpressing miR-497 or negative control cells, using Invitrogen TRIzol ${ }^{\mathbb{R}}$ reagent (Thermo Fisher Scientific, Inc.), according to the manufacturer's protocol. For the detection of miR-497, RT-qPCR was performed using SYBR Green Master Mix (Takara Biotechnology Co., Ltd., Dalian, China) and ABI PRISM $^{\circledR} 7500$ Sequence Detection System (Thermo Fisher Scientific, Inc.). Amplification of miR-497 and U6 was performed with 1 cycle at $95^{\circ} \mathrm{C}$ for $3 \mathrm{~min}$, followed by 30 cycles at $95^{\circ} \mathrm{C}$ for $10 \mathrm{sec}$ and $60^{\circ} \mathrm{C}$ for $10 \mathrm{sec}$. The primers (Takara Biotechnology Co., Ltd.) used were as follows: miR-497, forward 5'-GTGCAGGGTCCGAGGT-3' and reverse 5'-TAG CCTGCAGCACACTGTGGT-3'; and U6 (control), forward 5'-CTCGCTTCGGCAGCACATATACT-3' and reverse 5'-ACGCTTCACGAATTTGCGTGTC-3'. U6 small nuclear RNA was used as a normalization control. The relative expression of each gene was calculated and normalized using the $2^{-\Delta \Delta \mathrm{Cq}}$ method $(\mathrm{Cq}<35)(23)$.

Western blot analysis. The transfected cells were lysed $48 \mathrm{~h}$ subsequent to transfection using RIPA Lysis and Extraction Buffer (Thermo Fisher Scientific, Inc.), and the protein concentration was measured using Pierce ${ }^{\mathrm{TM}}$ BCA Protein Assay Kit (Thermo Fisher Scientific, Inc.). Following heating at $100^{\circ} \mathrm{C}$ for $10 \mathrm{~min}$ in the presence of a loading buffer, equal amounts of protein lysates $(50 \mu \mathrm{g})$ were separated using $10 \%$ sodium dodecyl sulfate-polyacrylamide gel electrophoresis (Bio-West Inc., Logan, UT, USA) at $100 \mathrm{~V}$ for $1 \mathrm{~h}$, and transferred onto Invitrogen nitrocellulose membranes (Thermo Fisher Scientific, Inc.) at $120 \mathrm{~V}$ for $1 \mathrm{~h}$. Following blocking with 5\% skimmed milk [diluted with phosphate-buffered saline (PBS); Sigma-Aldrich], the membranes were incubated overnight at $4^{\circ} \mathrm{C}$ with the following primary antibodies: i) Monoclonal rabbit anti-human matrix metalloproteinase (MMP)-2 (catalog no., 13132; dilution, 1:2,000; Cell Signaling Technology, Inc., Danvers, MA, USA); ii) monoclonal mouse anti-human MMP-9 (catalog no., sc-12759; dilution, 1:1,000; Santa Cruz Biotechnology, Inc., Dallas, TX, USA); iii) monoclonal mouse anti-human urokinase plasminogen activator (uPA; catalog no., sc-59729; dilution, 1:3,000; Santa Cruz Biotechnology, Inc.); and iv) anti-human glyceraldehyde-3-phosphate dehydrogenase (GAPDH; catalog no., sc-59729; dilution, 1:10,000; Santa Cruz Biotechnology, Inc.). GAPDH was used as a loading control. Subsequently, the membranes were incubated with secondary goat anti-mouse horseradish peroxidase-conjugated immunoglobulin G antibody (catalog no., sc-2005; dilution, 1:10,000; Santa Cruz Biotechnology, Inc.) at room temperature for $2 \mathrm{~h}$, and proteins were detected using enhanced chemiluminescence (Pierce ${ }^{\mathrm{TM}}$ ECL Western Blotting Substrate; Thermo Fisher Scientific, Inc.).

Proliferation analysis. In vitro cell proliferation was analyzed using Cell Counting Kit-8 (CCK-8; Dojindo Molecular Technologies, Inc., Kumamoto, Japan). Briefly, MG63 cells were transfected with a miR-497 mimic or negative control miRNA in 6 -well plates $\left(5 \times 10^{5}\right.$ cells/well). Following $24 \mathrm{~h}$, the cells were trypsinized (Sigma-Aldrich) and re-seeded in 96-well plates (Sigma-Aldrich) at a density of $1 \times 10^{3}$ cells/well. CCK-8 reagent $(10 \mu \mathrm{l} /$ well) was added at $0,24,48$ and $72 \mathrm{~h}$, and cells were incubated for $2.5 \mathrm{~h}$ at $37^{\circ} \mathrm{C}$. Optical density (OD) was measured at $450 \mathrm{~nm}$ using a microplate reader (Multiskan Spectrum; Thermo Labsystems, Helsinki, Finland). The experiment was performed $\geq 3$ times, and similar results were obtained.

Colony formation assay. For the colony formation assay, $24 \mathrm{~h}$ subsequent to transfection with miR-497 mimic or negative control miRNA, the cells were seeded in a 6-well plate at a low cell density (1,000 cells/well), and maintained in RPMI-1640 medium containing 10\% FCS for 2 weeks. The colonies were fixed with methanol (Sigma-Aldrich), and stained with $0.1 \%$ crystal violet (Sigma-Aldrich) diluted in $20 \%$ methanol for 15 min. Colony numbers were quantified using AlphaView software version 2.0 (ProteinSimple, San Jose, CA, USA), and the percentage of colony formation was calculated by adjusting the number of negative control cells to $100 \%$.

Cell cycle and cell apoptosis assay. The effects of miR-497 on the cell cycle and apoptosis of OS cells were examined using flow cytometry. Briefly, MG63 cells were transfected with a miR-497 mimic or negative control miRNA for $48 \mathrm{~h}$. Cell cycle progression was monitored using Cell Cycle Assay Kit (Fluorometric - Green) (catalogue number, ab112116; Abcam, Cambridge, MA, USA). The cells were acquired using $\mathrm{BD}^{\mathrm{TM}}$ LSR II flow cytometer (BD Biosciences, San Jose, CA, USA), and analyzed using Weasel version 3.1 software (available from http://www.frankbattye.com.au/Weasel/WeaselDownload.html). The percentage of cells undergoing apoptosis was determined with Annexin V staining and propidium iodide exclusion using BD Pharmingen ${ }^{\mathrm{TM}}$ FITC Annexin V Apoptosis Detection Kit I (BD Biosciences). The cells were acquired using $\mathrm{BD}^{\mathrm{TM}}$ LSR II flow cytometer, and analyzed using FACSDiva ${ }^{\mathrm{TM}}$ version 4.0 software (BD Biosciences).

Furthermore, the activity of caspase- 3 and caspase- 9 was investigated as an additional indicator of apoptosis using Caspase 3 Colorimetric Activity Assay Kit, DEVD and Caspase 9 Colorimetric Activity Assay Kit, LEHD, respectively (EMD Millipore, Billerica, MA, USA), according to the manufacturer's protocol. The relative caspase activity was calculated by adjusting the value obtained for the negative control cells to $100 \%$.

Transwell ${ }^{\circledR}$ migration and invasion assays. For the Transwell ${ }^{\circledR}$ migration assays, $1 \times 10^{5}$ transfected cells were plated in the top chamber of a Transwell ${ }^{\circledR}$ plate onto a non-coated membrane (24-well insert; pore size, $8 \mu \mathrm{m}$; Corning Inc., Corning, NY, USA). For the invasion assay, $1 \times 10^{5}$ transfected cells 
A

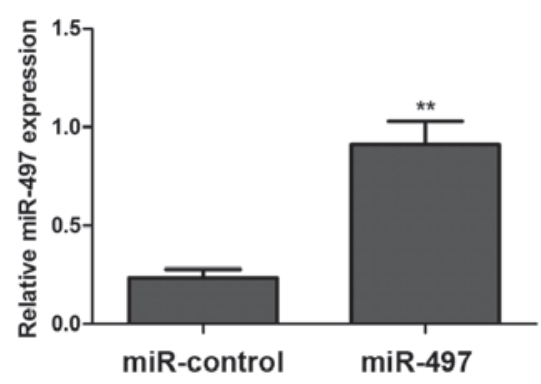

B

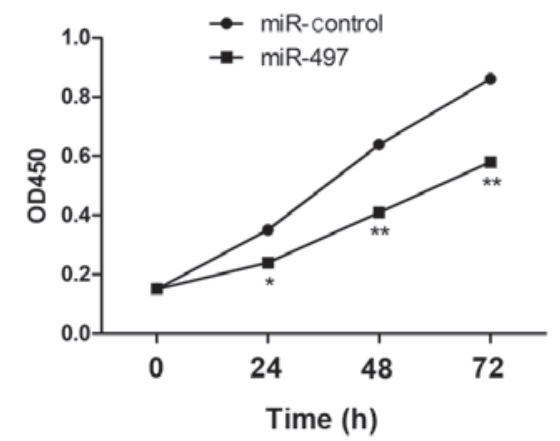

C

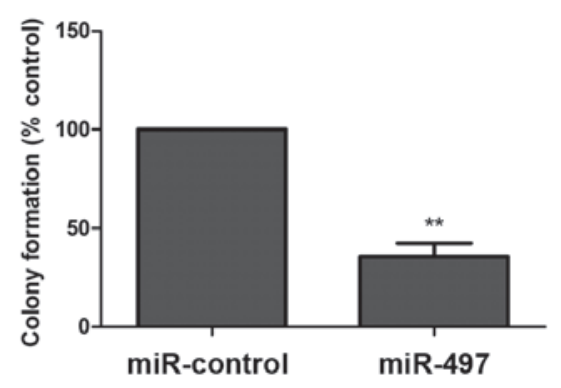

Figure 1. Overexpression of miR-497 inhibits cell proliferation and colony formation of human osteosarcoma MG63 cells. (A) Reverse transcription-quantitative polymerase chain reaction was performed to investigate the expression levels of miR-497 in MG63 cells $48 \mathrm{~h}$ subsequent to transfection with a miR-497 mimic or a negative control miR. (B) Cell Counting Kit-8 assay was performed to analyze the effect of miR-497 on the proliferation of MG63 cells. (C) The percentage of colony formation in tumor cells transfected with a miR-497 mimic was calculated by adjusting the percentage of tumor cells transfected with miR-control to $100 \%$. ${ }^{*} \mathrm{P}<0.05,{ }^{* *} \mathrm{P}<0.01$ vs. miR-control. miR, microRNA; OD, optical density.

were plated in the top chamber of a Transwell ${ }^{\circledR}$ plate onto a Matrigel $^{\mathrm{TM}}$-coated membrane. Each well was coated with $60 \mu \mathrm{g}$ BD Matrigel $^{\text {TM }}$ Basement Membrane Matrix (BD Biosciences) prior to the invasion assay. The cells were incubated for $24 \mathrm{~h}$ (migration assay) or $48 \mathrm{~h}$ (invasion assay). The cells that had migrated to the lower chamber of the Transwell ${ }^{\circledR}$ plate were fixed in 70\% ethanol (Sigma-Aldrich) for $30 \mathrm{~min}$, and stained with $0.2 \%$ crystal violet for $10 \mathrm{~min}$. The number of cells migrating or invading through the membrane were counted in five randomly selected fields under a light microscope (BX51; magnification, x200; Olympus Corp., Tokyo, Japan).

Tumor growth in vivo. A total of 20 male BALB/c mice (5-6 weeks old) were purchased from the Jilin Institute of Experimental Animals (Changchun, China), and were maintained under specific pathogen-free conditions at room temperature with a $12 \mathrm{~h}$ light/dark cycle and humidity of $60-70 \%$, and provided with food (Jilin Institute of Experimental Animals) and water ad libitum. Subsequently, $2 \times 10^{6}$ cells that were stably overexpressing miR-497 or negative control miRNA were suspended in $100 \mu \mathrm{l}$ PBS and injected into the flanks of the mice (overexpressing miR-497 group, $n=10$; negative control group, $n=10)$. The length and width of the resulting tumors were measured every 7 days using a digital caliper (Sigma-Aldrich). Tumor volume was calculated using the following formula: Tumor volume $\left(\mathrm{mm}^{3}\right)=0.5236 \mathrm{x}$ width $^{2} \mathrm{x}$ length. The mice were sacrificed 4 weeks subsequent to inoculation, and the tumors were resected and weighed. The tumors were used to measure the miR-497 expression levels using the aforementioned RT-qPCR method. All animal experiments were performed following the standards of animal care, as outlined in the Guide for the Care and Use of Laboratory Animals of Jilin University (Changchun, China), following a protocol approved by the Ethics Committee of Jilin University.

Statistical analysis. The data were presented as the mean \pm standard deviation of $\geq 3$ independent experiments. The differences between the groups were analyzed using Student's t test when there were 2 groups, or one-way analysis of variance when there were $\geq 2$ groups. The analyses were performed using GraphPad Prism version 5 software (GraphPad Software, Inc., La Jolla, CA, USA). P<0.05 was considered to indicate a statistically significant difference.

\section{Results}

miR-497 inhibits cell proliferation and colony formation in human OS MG63 cells. To examine the role of miR-497 in the growth of OS cells, MG63 cells were transfected with a miR-497 mimic or a negative control miRNA. Increased expression of miR-497 in cells transfected with the miR-497 mimic was confirmed using RT-qPCR (Fig. 1A). Overexpression of miR-497 significantly decreased the proliferation of cells, compared with negative control cells (Fig. 1B). In addition, miR-497 overexpression significantly inhibited colony formation, compared with the corresponding negative control (Fig. 1C). These results indicate that miR-497 exhibits a growth-inhibitory role in OS cells.

miR-497 induces G1 arrest and apoptosis in MG63 cells. In order to determine the effects of miR-497 on the cell cycle in MG63 cells, flow cytometry assays were performed. As revealed by Fig. 2A, overexpression of miR-497 increased the percentage of cells in the G1/G0 phase of the cell cycle, and decreased the percentage of cells in the $\mathrm{S}$ phase, compared with the negative control $(\mathrm{P}<0.05)$.

Subsequently, the role of miR-497 in the apoptosis of MG63 cells was assessed. There was a significantly increased percentage of apoptotic cells in the group that was overexpressing miR-497, compared with the corresponding negative control group $(\mathrm{P}<0.05$; Fig. $2 \mathrm{~B})$. In addition, the effects of miR-497 on caspase-3 and caspase- 9 activity were analyzed. As revealed by Fig. 2C and D, caspase- 3 and caspase- 9 activity was significantly increased in cells transfected with the miR-497 mimic, compared with cells transfected with the negative control $(\mathrm{P}<0.05)$. These results suggest that overexpression of miR-497 induces OS cells to arrest at the G0/G1 phase of the cell cycle and undergo apoptosis.

miR-497 inhibits cell migration and invasion in MG63 cells. Since miR-497 may act as a tumor suppressor, the present 
A

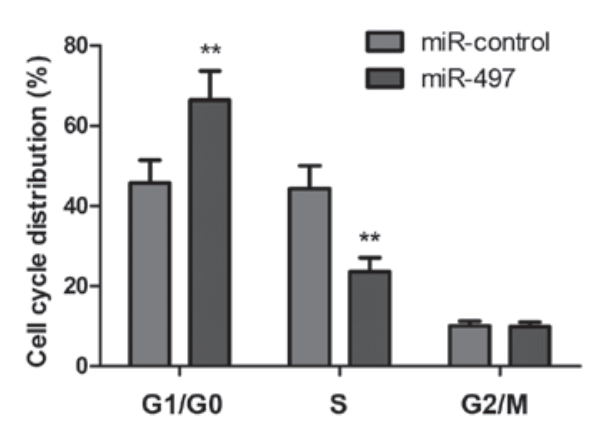

C

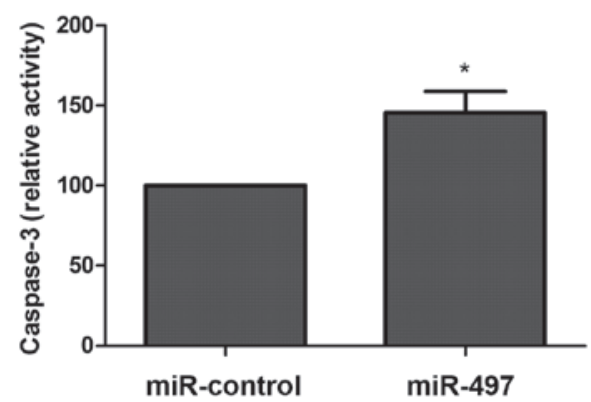

B

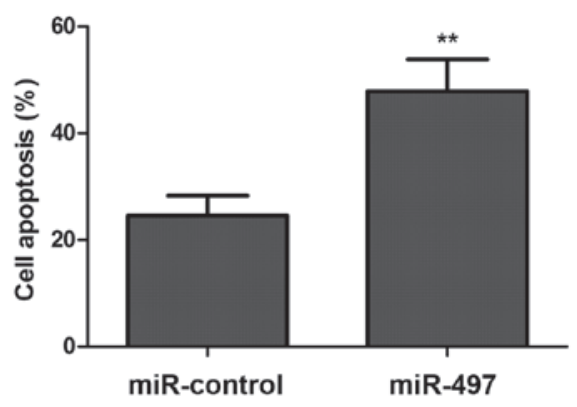

D

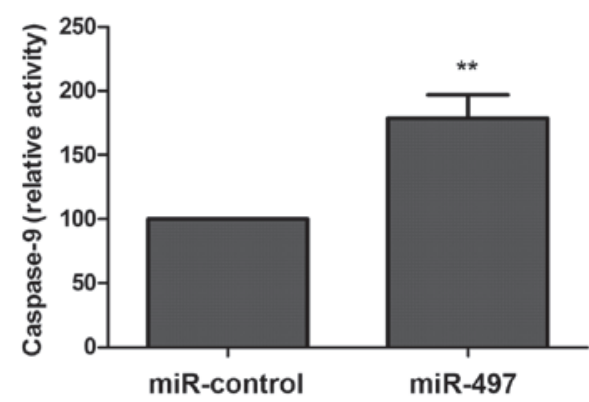

Figure 2. Overexpression of miR-497 induced human osteosarcoma MG63 cells to arrest at the G1 phase of the cell cycle and to undergo apoptosis. (A) MG63 cells were transfected with a miR-497 mimic or miR-control for 48 h, and subsequently collected for cell cycle analysis using Cell Cycle Assay Kit (Fluorometric - Green). (B) The effects of miR-497 on the apoptosis of MG63 cells were determined using flow cytometry. The activity of (C) caspase-3 and (D) caspase-9 in MG63 cells was determined following transfection with miR-497 mimic or miR-control. ${ }^{*} \mathrm{P}<0.05,{ }^{* *} \mathrm{P}<0.01$ vs. miR-control. miR, microRNA.

A

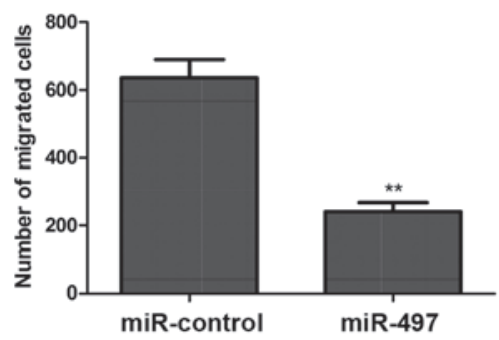

B

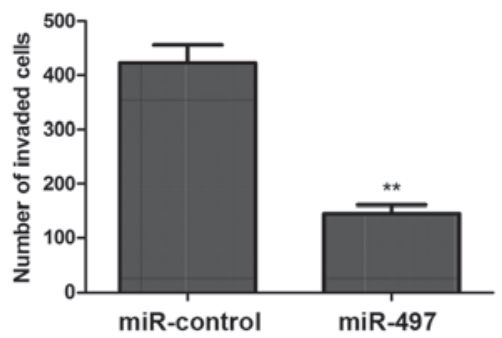

C

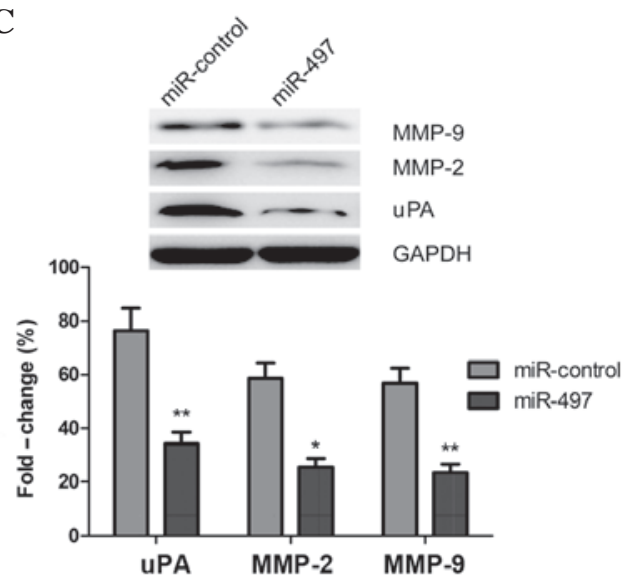

Figure 3. Overexpression of miR-497 inhibited the cell migration and invasion abilities of human osteosarcoma MG63 cells. (A) The number of migrated MG63 cells was determined using a Transwell ${ }^{\circledR}$ assay without Matrigel ${ }^{\mathrm{TM}} 24 \mathrm{~h}$ subsequent to transfection with miR-497 mimic or miR-control. (B) The number of invaded MG63 cells was determined using a Transwell ${ }^{\circledR}$ assay with Matrigel ${ }^{\mathrm{TM}} 48 \mathrm{~h}$ subsequent to transfection with miR-497 mimic or miR-control. (C) Western blot analysis of uPA, MMP-2 and MMP-9 protein expression following transfection with miR-497 mimic or miR-control. GAPDH was used as an internal control. "P<0.05, ${ }^{* *} \mathrm{P}<0.01$ vs. miR-control. miR, microRNA; MMP, matrix metalloproteinase; uPA, urokinase plasminogen activator; GAPDH, glyceraldehyde-3-phosphate dehydrogenase.

study investigated if restoration of miR-497 expression would affect the migration and invasion abilities of OS cells. A Transwell ${ }^{\circledR}$ assay without Matrigel ${ }^{\mathrm{TM}}$ demonstrated that the migratory ability of MG63 cells was markedly decreased in cells transfected with a miR-497 mimic, compared with cells transfected with negative control miRNA (Fig. 3A). Subsequently, a Transwell ${ }^{\circledR}$ assay with Matrigel $^{\mathrm{TM}}$ demonstrated that miR-497-transfected MG63 cells displayed significantly decreased invasive abilities, compared with the negative control group (Fig. 3B).
Furthermore, the present study analyzed the effects of miR-497 on the expression of uPA, MMP-2 and MMP-9 using western blot analysis. The results demonstrated that overexpression of miR-497 resulted in a significant decrease in the protein expression levels of UPA, MMP-2 and MMP-9, compared with cells transfected with a negative control $(\mathrm{P}<0.05$; Fig. 3C). These findings suggest that miR-497 inhibits the migratory and invasive abilities of OS cells in vitro by inhibiting the expression of UPA, MMP-2 and MMP-9. 
A

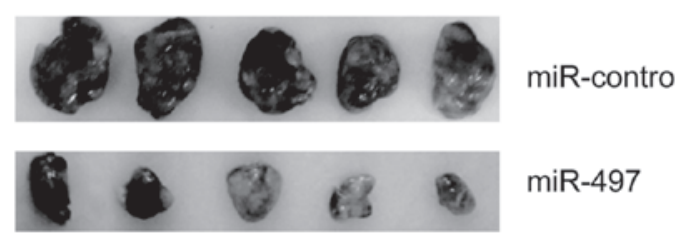

C

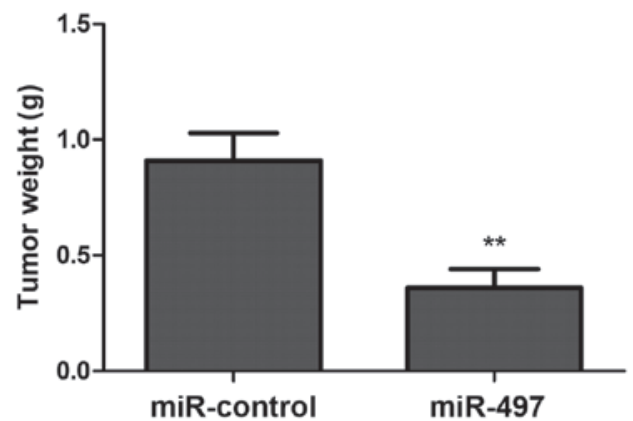

B

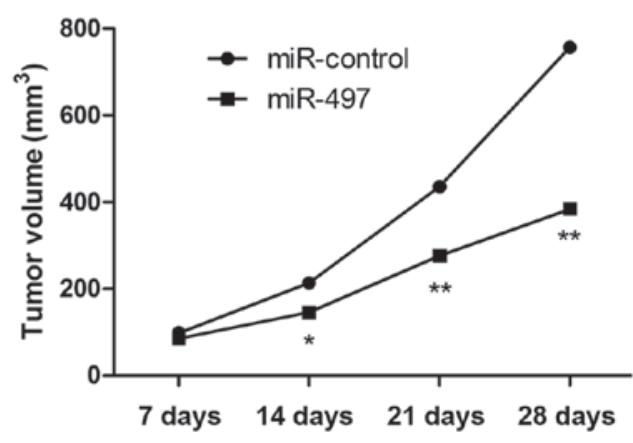

D

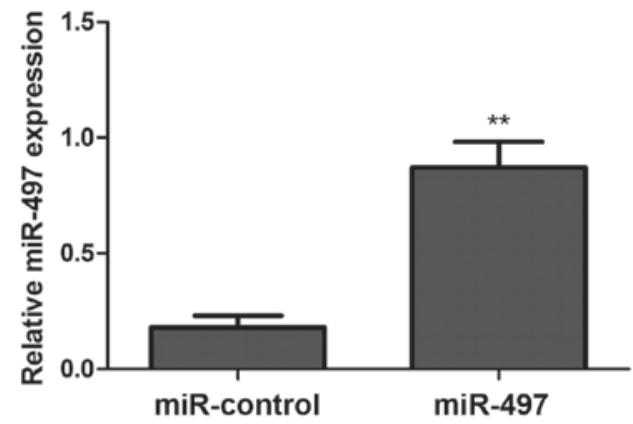

Figure 4. miR-497 inhibits tumor growth in vivo. (A) Representative image of tumors formed in BALB/c xenograft mouse models at 28 days following injection with human osteosarcoma MG63 cells transfected with a miR-497 mimic or miR-control. (B) Growth curve of tumors volume measured at the indicated times. (C) Weight of xenograft tumors. (D) Reverse transcription-quantitative polymerase chain reaction analysis of the expression levels of miR-497 in tumor tissues of miR-497 mimic and miR-control groups. ${ }^{*} \mathrm{P}<0.05,{ }^{* *} \mathrm{P}<0.01$ vs. miR-control. miR, microRNA.

miR-497 inhibits tumor growth in vivo. To examine the role of miR-497 in OS tumor development, the present study used a BALB/c xenograft mouse model. Mice were transplanted with MG63 cells overexpressing miR-497 or negative control miRNA. The mice were sacrificed, and the tumor tissues were excised 28 days subsequent to transplantation of the transfected MG63 cells. The results demonstrated that miR-497-overexpressing tumors were significantly smaller than tumors of mice transfected with negative control miRNA (Fig. 4A). In addition, overexpression of miR-497 significantly reduced xenograft tumor volume (Fig. 4B) and tumor weight (Fig. 4C), compared with the negative control group. To determine miR-497 transfection efficiency in the nude mouse model, the present study examined the expression levels of miR-497 in the xenograft tumors using RT-qPCR. The results revealed that miR-497 expression was upregulated in the xenograft tumors of mice injected with cells transfected with the miR-497 mimic, compared with tumors of mice injected with cells transfected with negative control miRNA (Fig. 4D). These results imply that overexpression of miR-497 may inhibit OS tumor growth in vivo.

\section{Discussion}

Increased expression of miR-497 has been demonstrated to suppress cancer cell proliferation, promote apoptosis, decrease migration and invasion, and increase chemosensitivity in cancer cells (16-22). However, the roles and mechanisms of miR-497 in OS remain unclear. To the best of our knowledge, the current study demonstrated for the first time that overexpression of miR-497 inhibited the proliferation, colony formation, migration and invasion abilities of OS cells, and increased the percentage of apoptotic cells in vitro. In addition, the present study demonstrated that restoration of miR-497 expression inhibited OS tumor growth in a nude mouse model. These results suggest that miR-497 inhibits tumor growth in vitro and in vivo, as previously reported (16-21).

Previous studies have revealed that tumor suppressor miRNAs are involved in the carcinogenesis and tumor progression of OS, and exert tumor suppressor effects in OS. Li et al (24) reported that miRNA-145 acts as a tumor suppressor by inhibiting OS cell growth through suppression of rho-associated, coiled-coil-containing protein kinase 1 . Sun et al (25) reported that upregulation of miRNA-646 expression inhibited OS cell proliferation, migration and invasion by downregulating fibroblast growth factor-2. In addition, Zhao et al (26) demonstrated that transfection of a miRNA-410 expression plasmid into OS cells inhibited cell proliferation and contributed to cell apoptosis by regulating vascular endothelial growth factor (VEGF). Zhang et al (27) revealed that miRNA-101 may act as a tumor suppressor in OS, since it has a suppressive role in OS cell migration and invasion by targeting enhancer of zeste homolog 2. miR-497, another potential tumor suppressor, has been demonstrated to be downregulated in OS cells (21). The present study identified that overexpression of miR-497 inhibited the tumor growth of OS cells in vitro and in vivo, which suggests that miR-497 may be a promising therapeutic target for the treatment of patients with OS.

miRNAs are key in the regulation of cancer cell proliferation, cell cycle distribution, migration and invasion by regulating multiple target genes (28). Several targets have been identified that are essential in cell cycle and 
survival pathways, including insulin-like growth factor 1 receptor (17,18), WEE1 G2 checkpoint kinase (19), B-cell lymphoma-2 (29), cyclin D2 (30) and VEGF (31). Previously, checkpoint kinase 1 and hepatoma-derived growth factor were also identified as target genes for miR-497 $(32,33)$. Therefore, the present study hypothesizes that miR-497 inhibits OS cell proliferation, clonogenicity, migration and invasion, and induces OS cell apoptosis and cell arrest at the G0/G1 phase of the cell cycle by regulating multiple target genes.

In summary, the results of the present study indicate that overexpression of miR-497 in OS cells is able to inhibit OS cell proliferation, colony formation, migration and invasion, and induce G1 phase arrest and apoptosis of OS cells in vitro. In addition, the present study revealed that overexpression of miR-497 suppresses OS tumor growth in a xenograft mouse model. Therefore, these findings suggest that miR-497 may be a potential molecular target for OS therapy.

\section{References}

1. Ottaviani G, Robert RS, Huh WW, Palla S and Jaffe N: Sociooccupational and physical outcomes more than 20 years after the diagnosis of osteosarcoma in children and adolescents: Limb salvage versus amputation. Cancer 119: 3727-3736, 2013.

2. Ottaviani G and Jaffe N: The etiology of osteosarcoma. Cancer Treat Res 152: 15-32, 2009.

3. PosthumaDeBoer J, Witlox MA, Kaspers GJ and van Royen BJ: Molecular alterations as target for therapy in metastatic osteosarcoma: A review of literature. Clin Exp Metastasis 28: 493-503, 2011.

4. Chou AJ, Kleinerman ES, Krailo MD, Chen Z, Betcher DL, Healey JH, Conrad EU III, Nieder ML, Weiner MA, Wells RJ, et al; Children's Oncology Group: Addition of muramyl tripeptide to chemotherapy for patients with newly diagnosed metastatic osteosarcoma: A report from the Children's Oncology Group. Cancer 115: 5339-5348, 2009.

5. Grignani G, Palmerini E, Dileo P, Asaftei SD, D'Ambrosio L, Pignochino Y, Mercuri M, Picci P, Fagioli F, Casali PG, et al: A phase II trial of sorafenib in relapsed and unresectable high-grade osteosarcoma after failure of standard multimodal therapy: An Italian Sarcoma Group study. Ann Oncol 23: 508-516, 2012.

6. Luetke A, Meyers PA, Lewis I and Juergens H: Osteosarcoma treatment - where do we stand? A state of the art review. Cancer Treat Rev 40: 523-532, 2014.

7. Bartel DP: MicroRNAs: Genomics, biogenesis, mechanism, and function. Cell 116: 281-297, 2004.

8. Kato M and Slack FJ: MicroRNAs: Small molecules with big roles - C. elegans to human cancer. Biol Cell 100: 71-81, 2008.

9. Kloosterman WP and Plasterk RH: The diverse functions of microRNAs in animal development and disease. Dev Cell 11: 441-450, 2006

10. Iorio MV and Croce CM: MicroRNA dysregulation in cancer: Diagnostics, monitoring and therapeutics. A comprehensive review. EMBO Mol Med 4: 143-159, 2012.

11. Nana-Sinkam SP and Croce CM: MicroRNA dysregulation in cancer: Opportunities for the development of microRNA-based drugs. IDrugs 13: 843-846, 2010.

12. Suzuki H, Maruyama R, Yamamoto E and Kai M: Epigenetic alteration and microRNA dysregulation in cancer. Front Genet 4: 258, 2013

13. Cho WC: OncomiRs: The discovery and progress of microRNAs in cancers. Mol Cancer 6: 60, 2007.

14. Finnerty JR, Wang WX, Hébert SS, Wilfred BR, Mao G and Nelson PT: The miR-15/107 group of microRNA genes: Evolutionary biology, cellular functions, and roles in human diseases. J Mol Biol 402: 491-509, 2010.
15. Wang W, Ren F, Wu Q, Jiang D, Li H, Peng Z, Wang J and Shi H: MicroRNA-497 inhibition of ovarian cancer cell migration and invasion through targeting of SMAD specific E3 ubiquitin protein ligase 1. Biochem Biophys Res Commun 449: 432-437, 2014

16. Li D, Zhao Y, Liu C, Chen X, Qi Y, Jiang Y, Zou C, Zhang X, Liu S, Wang X, et al: Analysis of MiR-195 and MiR-497 expression, regulation and role in breast cancer. Clin Cancer Res 17: 1722-1730, 2011.

17. Luo M, Shen D, Zhou X, Chen X and Wang W: MicroRNA-497 is a potential prognostic marker in human cervical cancer and functions as a tumor suppressor by targeting the insulin-like growth factor 1 receptor. Surgery 153: 836-847, 2013.

18. Guo ST, Jiang CC, Wang GP, Li YP, Wang CY, Guo XY, Yang RH, Feng Y, Wang FH, Tseng HY, et al: MicroRNA-497 targets insulin-like growth factor 1 receptor and has a tumour suppressive role in human colorectal cancer. Oncogene 32: 1910-1920, 2013.

19. Creevey L, Ryan J, Harvey H, Bray IM, Meehan M, Khan AR and Stallings RL: MicroR NA-497 increases apoptosis in MYCN amplified neuroblastoma cells by targeting the key cell cycle regulator WEE1. Mol Cancer 12: 23, 2013.

20. Li W, Jin X, Deng X, Zhang G, Zhang B and Ma L: The putative tumor suppressor microRNA-497 modulates gastric cancer cell proliferation and invasion by repressing eIF4E. Biochem Biophys Res Commun 449: 235-240, 2014.

21. Wang W, Ren F, Wu Q, Jiang D, Li H and Shi H: MicroRNA-497 suppresses angiogenesis by targeting vascular endothelial growth factor A through the PI3K/AKT and MAPK/ERK pathways in ovarian cancer. Oncol Rep 32: 2127-2133, 2014.

22. Namløs HM, Meza-Zepeda LA, Barøy T, Østensen IH, Kresse SH, Kuijjer ML, Serra M, Bürger H, Cleton-Jansen AM and Myklebost O: Modulation of the osteosarcoma expression phenotype by microRNAs. PLoS One 7: e48086, 2012.

23. Livak KJ and Schmittgen TD: Analysis of relative gene expression data using real-time quantitative PCR and the 2(-Delta Delta C(T)) Method. Methods 25: 402-408, 2001.

24. Li E, Zhang J, Yuan T and Ma B: MiR-145 inhibits osteosarcoma cells proliferation and invasion by targeting ROCK1. Tumour Biol 35: 7645-7650, 2014.

25. Sun XH, Geng XL, Zhang J and Zhang C: miRNA-646 suppresses osteosarcoma cell metastasis by downregulating fibroblast growth factor 2 (FGF2). Tumour Biol 36: 2127-2134, 2015.

26. Zhao D, Jia P, Wang W and Zhang G: VEGF-mediated suppression of cell proliferation and invasion by miR-410 in osteosarcoma. Mol Cell Biochem 400: 87-95, 2015.

27. Zhang K, Zhang Y, Ren K, Zhao G, Yan K and Ma B: MicroRNA-101 inhibits the metastasis of osteosarcoma cells by downregulation of EZH2 expression. Oncol Rep 32: 2143-2149, 2014

28. Calin GA and Croce CM: MicroRNA signatures in human cancers. Nat Rev Cancer 6: 857-866, 2006.

29. Zhu W, Zhu D, Lu S, Wang T, Wang J, Jiang B, Shu Y and Liu P: miR-497 modulates multidrug resistance of human cancer cell lines by targeting BCL2. Med Oncol 29: 384-391, 2012.

30. Yadav S, Pandey A, Shukla A, Talwelkar SS, Kumar A, Pant AB and Parmar D: miR-497 and miR-302b regulate ethanol-induced neuronal cell death through BCL2 protein and cyclin D2. J Biol Chem 286: 37347-37357, 2011.

31. Zhou TB, Jiang ZP, Liu ZS and Zhao ZZ: Roles of miR-497 and its potential signaling pathway in diseases and with vascular endothelial growth factor. J Recept Signal Transduct Res 35: 303-306, 2015.

32. Xie Y, Wei RR, Huang GL, Zhang MY, Yuan YF and Wang HY: Checkpoint kinase 1 is negatively regulated by miR-497 in hepatocellular carcinoma. Med Oncol 31: 844, 2014.

33. Zhao WY, Wang Y, An ZJ, Shi CG, Zhu GA, Wang B, Lu MY, Pan CK and Chen P: Downregulation of miR-497 promotes tumor growth and angiogenesis by targeting HDGF in non-small cell lung cancer. Biochem Biophys Res Commun 435: 466-471, 2013. 